ORIGINAL ARTICLE

\title{
Prevalence of respiratory symptoms among female flight attendants and teachers
}

\author{
E A Whelan, C C Lawson, B Grajewski, M R Petersen, L E Pinkerton, E M Ward, T M Schnorr
}

Occup Environ Med 2003;62:929-934

See end of article for authors' affiliations ....................

Correspondence to: Dr E A Whelan, Industrywide Stúdies Branch, DSHEFS, NIOSH 4676 Columbia Parkway, R-15, Cincinnati, Ohio 45226, USA

EWhelan@cdc.gov

Accepted 11 January 2003
Background: Potential health effects of the indoor environment in office buildings and aircraft have generated considerable concern in recent years.

Aims: To analyse the prevalence of self reported respiratory symptoms and illnesses in flight attendants (FAs) and schoolteachers.

Methods: Data were collected as part of a study of reproductive health among female FAs. The prevalences of work related eye, nose, and throat symptoms, wheezing, physician diagnosed asthma, chest illness, and cold or flu were calculated and stratified by smoking status in 1824 FAs and 331 schoolteachers.

Results: FAs and teachers were significantly more likely to report work related eye $12.4 \%$ and $7.4 \%$, respectively), nose (15.7\% and $8.1 \%)$, and throat symptoms $(7.5 \%$ and $5.7 \%)$ than were other working women $(2.9 \%$ eye, $2.7 \%$ nose, and $1.3 \%$ throat symptoms). FAs were significantly more likely than teachers and referent working women to report chest illness during the prior three years $132.9 \%, 19.3 \%$, $7.2 \%$, respectively). Both study groups were more likely to report five or more episodes of cold or flu in the past year than were other working women (10.2\% of FAs, $8.2 \%$ of teachers, $2.3 \%$ of referents), and both groups were more likely to report wheezing than other working women (22.8\% of FAs, $28.4 \%$ of teachers, $16.4 \%$ of referents). FAs were significantly less likely than teachers and other working women to report ever having been diagnosed with asthma (8.2\%, 13.3\%, $11.8 \%$, respectively).

Conclusions: Overall, FAs and schoolteachers report a higher prevalence of work related upper respiratory symptoms, chest illness, and cold or flu than the general working population.

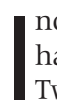
ndoor air quality in occupational and residential settings has generated considerable concern over the past decade. Two occupational groups that have been a focus of recent interest in the United States are flight attendants ${ }^{1}$ and schoolteachers. ${ }^{2}$ Indoor air quality problems in aircraft cabins and in schools may differ from those in commercial office buildings because occupant density in the former settings is generally higher. ${ }^{3}$ The aircraft cabin environment is also characterised by reduced air pressure and humidity, passage of the air supply first through an aircraft engine, shift lengths for flight attendants that can legally exceed 14 hours, and the inability of occupants to leave at will. In many municipal schools, heating, ventilation, and air conditioning (HVAC) systems are often malfunctioning or, in some cases, nonexistent. ${ }^{4}$

We included a series of respiratory symptom questions in a study of reproductive health among female flight attendants in the USA. Since female teachers were enrolled as a comparison group for the analyses of reproductive health outcomes, they provided a second occupational group from which to collect respiratory symptom data. We present here the self reported prevalence of respiratory symptoms and illnesses in these two occupational groups. Background data from national or other large surveys are presented for comparison.

\section{METHODS}

\section{Study population and data collection}

Three major US airline companies with domiciles (or hubs) in Miami, Seattle, and Detroit were selected for this study. The companies provided lists of all full time, female flight attendants aged 18-45 who were based at these domiciles. Rosters of potentially eligible female classroom teachers of grades 5-12 were obtained from local school districts in the same three geographic regions as the flight attendants. Teachers were selected as a comparison group for the reproductive health study because this predominantly female occupation has minimal air travel, few reproductive hazards, and comparability to flight attendants on several key demographic characteristics (for example, age, race, education, parity). ${ }^{5}$

A telephone screener was used to determine eligibility according to the following criteria: (1) age 18-45 years during the study period for the main part of the study ( 1 August 1992 to 31 July 1996); (2) full time employment as a flight attendant or teacher for at least one month during the study period; (3) in a marital relationship any time during the study period; and (4) not surgically sterilised prior to the study period. The latter two criteria were imposed for the purpose of the reproductive health analyses. The current analysis was restricted to women who were employed as a flight attendant or teacher at the time of the interview. Teachers were restricted to grades 5-12 to minimise inclusion of women with high likelihood of exposure to infectious agents from working with young children.

\section{Interview}

Interviews were conducted between 1999 and 2001 by trained interviewers using a computer assisted telephone interview system. Questions on eye, nose, and throat symptoms were based on items from the 1988 National Health Interview Survey (NHIS) occupational health supplement $^{6}$ (see Appendix for questions). For these questions, respondents were asked whether their symptoms improved on days when they were away from work. Items on wheezing or whistling in the chest and cold or flu were based on similar items from the National Health and Nutrition Examination Survey III (NHANES III). ${ }^{7}$ The question on chest illness was a 


\section{Main messages}

- Increasing interest in issues related to airline cabin air quality led to inclusion of respiratory symptom questions in a large study of flight attendants and schoolteachers. The questions were derived from national surveys, allowing comparison with normative data from other working women.

- Both flight attendants and teachers reported a higher prevalence of work related upper respiratory symptoms, wheezing, chest illness, and colds/flu than did other working women of the same age range.

- Flight attendants were significantly less likely than teachers and other working women to report physician diagnosed asthma.

- Limitations of the study include the self reported nature of the data and the absence of environmental measures with which to link the reported symptoms.

modified version of an item from the respiratory symptoms questionnaire developed by the Medical Research Council (MRC) of Great Britain. ${ }^{89}$ Questions on asthma were modified versions of those asked in the 2000 Behavioral Risk Factor Surveillance System survey (BRFSS). ${ }^{10}$ Demographic information and smoking history were also collected during the interview.

\section{Analysis}

Prevalence rates for each symptom were calculated, stratified by smoking status. The national surveys that served as sources of the questions (the 1988 NHIS Occupational Health Supplement, the NHANES III, and the 2000 BRFSS) provided external comparison data. Data for North Carolina blue collar workers with no known occupational exposures were used as the external comparison group for chest illness. ${ }^{9}$ Comparison groups were restricted to women who were of the same age range as the study population (age 24-49) and who were currently working. Weighted prevalence estimates and standard errors for the national data were calculated using SUDAAN to account for the complex survey designs. ${ }^{11}$ All other analyses were performed using SAS version $8 .{ }^{12}$ Flight attendants, teachers, and the North Carolina blue collar workers were compared using $t$ and $\chi^{2}$ tests. Comparisons of flight attendants and teachers with external groups were performed using $\mathrm{z}$ tests.

\section{RESULTS}

Table 1 provides the details of subject recruitment and response rate. Approximately $20 \%$ of the target population could not be contacted, primarily because an address or telephone number could not be identified. Of those contacted,

Table 1 Study population and response rate

\begin{tabular}{llll}
\hline & Flight attendants & Teachers & All \\
\hline Target population & 6376 & 2012 & 8388 \\
Contacted & $5096(80 \%)$ & $1582(79 \%)$ & $6678(80 \%)$ \\
Eligible* & $2595(51 \%)$ & $466(29 \%)$ & $3061(46 \%)$ \\
Respondents & $2273(88 \%)$ & $381(82 \%)$ & $2654(87 \%)$ \\
Employed at time of & $1824(80 \%)$ & $331(87 \%)$ & $2155(81 \%)$ \\
interview & & & \\
\hline
\end{tabular}

*Reasons for ineligibility included unmarried status during the study period $(78 \%)$, not working as a flight attendant or teacher during study period $(11 \%)$, surgical sterilisation prior to study period $(9 \%)$, and age out of eligible range $(2 \%)$.

\section{Policy implications}

- The findings from this study should be confirmed and potential causes of the apparently high prevalence of symptoms in these occupational groups should be the subject of further study.

$49 \%$ of flight attendants and $71 \%$ of teachers were not eligible for the reproductive health study, primarily because of marital status. Of the eligible women, $88 \%$ of flight attendants and $82 \%$ of teachers agreed to be interviewed, for an overall response rate of $87 \%$. A total of 2155 women (1824 flight attendants and 331 teachers) were employed at the time of the interview and therefore were included in the analysis of respiratory symptoms.

Table 2 provides the demographic characteristics of participants in the respiratory symptom analysis. Teachers were slightly older and somewhat less likely to be of Hispanic ethnicity compared to flight attendants. Flight attendants had a lower body mass index compared to teachers $(21.8 \mathrm{v}$ $25.8 \mathrm{~kg} / \mathrm{m}^{2}$, respectively). The majority of participants in both groups were never smokers, and approximately $9 \%$ in each group were current cigarette smokers. Flight attendants had a slightly longer job tenure than teachers.

The prevalence of respiratory symptoms among study participants is shown in table 3 and prevalence ratios are provided in fig 1 . Flight attendants and teachers were both significantly more likely to report work related eye, nose, and throat symptoms, chest illness, and colds or flu than were working women in the external comparison populations. Flight attendants were significantly more likely than teachers to report chest illness (33\% v 19.3\%, respectively). When the prevalence of these symptoms was examined by month of interview, no seasonal pattern was observed, nor was there any pattern by smoking status.

Flight attendants were significantly less likely to report ever having been diagnosed with asthma compared to teachers or working women in the BRFSS (table 3 and fig 1). Teachers with a higher body mass index (BMI) $(\geqslant 25$ $\mathrm{kg} / \mathrm{m}^{2}$ ) were almost twice as likely to report that they currently had asthma compared to teachers with a lower BMI (data not shown). There was little difference in asthma by BMI among flight attendants. Among smokers, teachers were less likely than working women in the BRFSS to report that they currently had asthma $(3.1 \% \vee 9.7 \%$, respectively; data not shown). Among ex-smokers and non-smokers, this difference was not observed.

Flight attendants and teachers were both significantly more likely to report wheezing or whistling in the chest in the past year compared to the working women in NHANES

Table 2 Demographic characteristics of flight attendants and teachers in the respiratory symptom analysis

\begin{tabular}{lll}
\hline Characteristic & $\begin{array}{l}\text { Flight attendants } \\
\text { (n= 1824) }\end{array}$ & $\begin{array}{l}\text { Teachers } \\
\text { (n=331) }\end{array}$ \\
\hline Age at interview (years; mean (SD)) & $38.2(4.8)$ & $40.3(5.9)$ \\
Non-white (\%) & 16.0 & 15.1 \\
Hispanic ethnicity (\%) & 6.9 & 4.8 \\
Education: post high school (\%) & 85.1 & 99.1 \\
Body mass index (kg/m ${ }^{2}$; mean (SD)) & $21.8(2.6)$ & $25.8(5.7)$ \\
Smoking & 70.4 & 66.8 \\
$\quad$ Never (\%) & 20.4 & 23.6 \\
$\quad$ Ex-smoker (\%) & 9.1 & 9.7 \\
Current (\%) & $13.0(4.9)$ & $11.1(7.3)$ \\
Job tenure (years; mean (SD)) & & \\
\hline \multirow{2}{*}{ SD, standard deviation. } & &
\end{tabular}


Table 3 Prevalence of respiratory symptoms among flight attendants, teachers, and working women (aged 24-49)

\begin{tabular}{|c|c|c|c|c|c|c|}
\hline \multirow[b]{2}{*}{ Symptom (\%) } & \multirow{2}{*}{$\begin{array}{l}\text { Flight attendants (FA) } \\
\text { ( } \mathrm{n}=1824 \text { ) }\end{array}$} & \multirow{2}{*}{$\begin{array}{l}\text { Teachers (T) } \\
(\mathrm{n}=331)\end{array}$} & \multirow{2}{*}{$\begin{array}{l}\text { Comparison } \\
\text { women }(\mathrm{C})^{*}\end{array}$} & \multicolumn{3}{|l|}{ p value } \\
\hline & & & & FA $v$ T & FA $v$ C & $\mathrm{T} \vee \mathrm{C}$ \\
\hline Itchy, irritated, or watery eyes in prior 2 weeks & 12.4 & 7.4 & $2.9(0.2)$ & 0.02 & $<0.005$ & 0.01 \\
\hline Stuffed, itchy, or runny nose in prior 2 weeks & 15.7 & 8.1 & $2.7(0.2)$ & $<0.005$ & $<0.005$ & $<0.005$ \\
\hline Sore or dry throat in prior 2 weeks & 7.5 & 5.7 & $1.3(0.1)$ & 0.28 & $<0.005$ & $<0.005$ \\
\hline Chest illness in past 3 years & 32.9 & 19.3 & $7.2(1.3)$ & $<0.005$ & $<0.005$ & $<0.005$ \\
\hline Cold or flu (5+ episodes in past year) & 10.2 & 8.2 & $2.3(0.4)$ & 0.26 & $<0.005$ & $<0.005$ \\
\hline Ever had asthma diagnosed by a physician & 8.2 & 13.3 & $11.8(0.3)$ & $<0.005$ & $<0.005$ & 0.42 \\
\hline Currently have physician diagnosed asthma & 4.9 & 8.8 & $8.6(0.3)$ & $<0.005$ & $<0.005$ & 0.90 \\
\hline
\end{tabular}

*Source of comparison data varies by symptom: 1988 NHIS Occupational Health Supplement (for eyes, nose, and throat; $n=9304$ ), the 1988-94 NHANES III (for cold or flu; $n=2786$ ), the 2000 BRFSS (for asthma; $n=41988$ ), and 1984 data for non-exposed blue collar workers in North Carolina (for chest illness; $n=416$ ). Standard error (SE) in parentheses.

(table 4 and fig 1). Teachers reported a higher prevalence of chest wheezing or whistling than did flight attendants, but the difference was largely restricted to smokers, where $50 \%$ of teachers reported this symptom compared to $31.9 \%$ of flight attendants. Differences in BMI between flight attendants and teachers did not explain the higher prevalence of these symptoms among teachers (data not shown).

We questioned whether the higher prevalence of wheezing among flight attendants might be related to their higher prevalence of colds and flu. We therefore examined the prevalence of wheezing stratified by episodes of cold/flu (less than five and five or more). The prevalence of wheezing was similar between flight attendants and NHANES women in the high cold/flu category ( $35 \%$ and $36 \%$, respectively), but in the low cold/flu category, flight attendants were still somewhat more likely to report wheezing than were NHANES women $(21 \%$ and $16 \%$, respectively). Thus, the high prevalence of wheezing in flight attendants is not entirely explained by the fact that they report more colds and flu.

Because the study interviews were conducted throughout the calendar year, a subanalysis was conducted restricting the teacher interviews to only those that occurred between September and May (that is, the usual school year). No substantive differences in the findings were noted.

\section{DISCUSSION}

To our knowledge, this is the first examination of respiratory symptoms among flight attendants and teachers using standard questions derived from national or other large surveys. This approach enabled comparison of our study data with normative data from other working women. The findings suggest that both flight attendants and teachers experience upper respiratory symptoms, chest illness, cold or flu, and wheezing as a result of their occupational environment. The flight attendants and teachers had very similar smoking habits (about 9\% in each group were current smokers), but the referent women were more than twice as likely to be current smokers. When comparing flight attendants and teachers with referent women, few differences by smoking status were noted.

The lower prevalence of asthma but higher prevalence of wheezing among flight attendants compared to the general population seems paradoxical. Flight attendants are not required to undergo medical screening prior to employment except to show that they are able to perform the duties of the job. One plausible explanation for a lower prevalence of asthma among flight attendants is that individuals with chronic conditions like asthma may self select out of this occupation.

The air cabin environment represents a unique occupational setting. Among the possible causes of the symptoms reported by crew (and passengers) are the cabin environment itself (for example, cabin pressure and relative humidity), contaminants (for example, ozone, pesticides, biological agents, constituents of engine lubricating oils, and hydraulic fluids and their heated by-products), and physiological stressors (for example, fatigue, cramped space, and disrupted circadian rhythms). ${ }^{1}$ In a study of commercial aircraft cabins (Waters et al, submitted), more than $86 \%$ of the gate-to-gate flight average carbon dioxide $\left(\mathrm{CO}_{2}\right)$ concentrations exceeded 1000 ppm, a level above which increased building related symptoms have been shown, ${ }^{13}$ and 39\% exceeded $1500 \mathrm{ppm}$. Up to $50 \%$ of the cabin air on newer aircraft is filtered and recycled or recirculated. The primary method of controlling

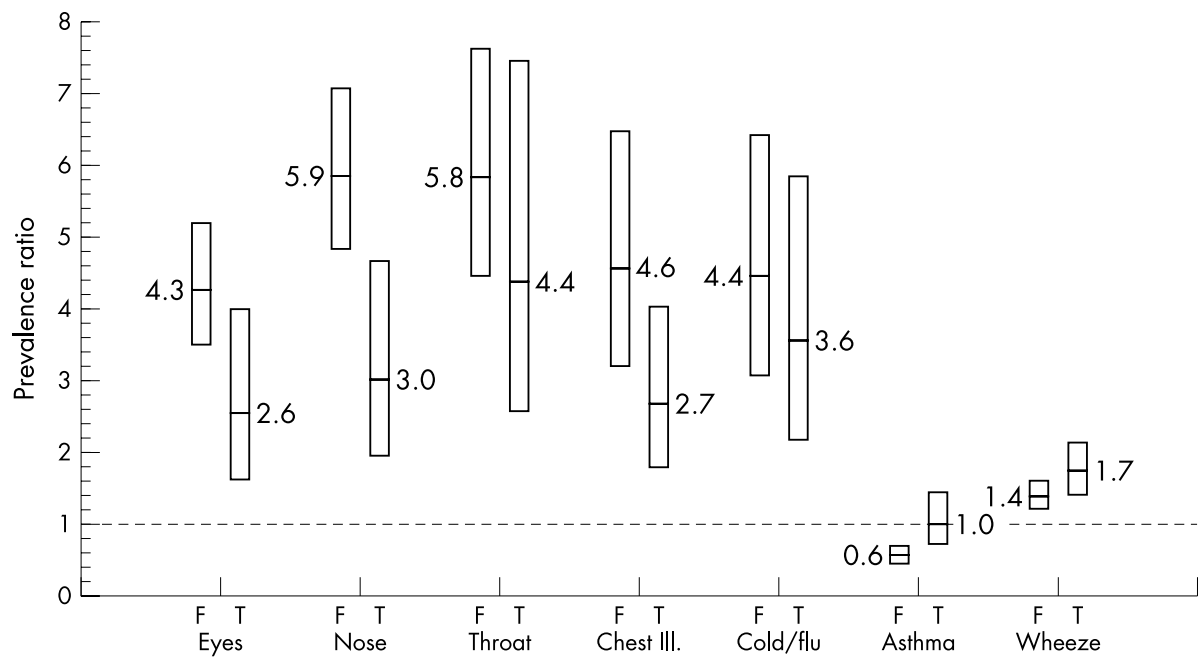

Figure 1 Prevalence ratios (and 95\% Cl) for respiratory symptoms reported by flight attendants (F) and teachers (T). Prevalence ratios are relative to the external population. 
Table 4 Prevalence of wheezing or whistling in the chest in the past 12 months and number of episodes among flight attendants, teachers, and working women (aged 24-49) in the National Health and Nutrition Examination Survey III

\begin{tabular}{|c|c|c|c|c|c|c|}
\hline & \multirow[b]{2}{*}{$\begin{array}{l}\text { Flight attendants (FA) } \\
(n=1824)\end{array}$} & \multirow[b]{2}{*}{$\begin{array}{l}\text { Teachers (T) } \\
(n=331)\end{array}$} & \multirow{2}{*}{$\begin{array}{l}\text { NHANES III } \\
\text { Working women (C) } \\
(\mathrm{n}=2786)^{*}\end{array}$} & \multicolumn{3}{|l|}{$p$ value } \\
\hline & & & & $\mathrm{FA} v \mathrm{~T}$ & $\mathrm{FA} v \mathrm{C}$ & $\mathrm{T} v \mathrm{C}$ \\
\hline \multicolumn{7}{|c|}{ Wheezing/whistling in the chest (\%) } \\
\hline All & 22.8 & 28.4 & 16.4 (SE 0.9) & 0.03 & $<0.005$ & $<0.005$ \\
\hline Never smoker & 20.6 & 24.9 & 10.6 (SE 0.9) & 0.15 & $<0.005$ & $<0.005$ \\
\hline Ex-smoker & 26.4 & 29.5 & 14.3 (SE 2.7) & 0.58 & $<0.005$ & 0.01 \\
\hline Smoker & 31.9 & 50.0 & 29.6 (SE 2.2) & 0.05 & 0.58 & 0.02 \\
\hline \multicolumn{7}{|c|}{ Number of episodes of wheezing/whistling in the chest (GM (GSE)) } \\
\hline All & $2.7(1.1)$ & $4.0(1.1)$ & $3.3(1.1)$ & $<0.005$ & 0.12 & 0.28 \\
\hline Never smoker & $2.7(1.1)$ & $4.0(1.2)$ & $2.3(1.2)$ & $<0.005$ & 0.64 & 0.01 \\
\hline Ex-smoker & $2.8(1.1)$ & $3.7(1.3)$ & 3.7 (1.3) & 0.36 & 0.44 & 0.99 \\
\hline Current smoker & $2.8(1.1)$ & $3.9(1.4)$ & $4.0(1.2)$ & 0.15 & 0.10 & 0.82 \\
\hline
\end{tabular}

the concentrations of cabin air contaminants is the provision of outside, or "bleed" air. ${ }^{14}$ An aeroplane's environmental control system can be a source of contamination, particularly under abnormal operating conditions. ${ }^{1}$ Engine lubricating oils, hydraulic fluid, or de-icing fluids can unintentionally enter the cabin through the bleed air supply system from the engine. Laboratory data suggest that many compounds are released when these fluids are heated to the high temperatures that occur in the bleed air system. ${ }^{15} 16$

Research on the association of cabin air quality with health complaints of cabin crew is sparse. The majority of data about symptoms come from reports filed by cabin crews, which are not gathered systematically, but are primarily filed in response to air quality incidents. One study reported that symptoms recorded were consistent with possible exposure to ozone, ${ }^{17}$ but the response rate to the survey was low (55\%), and no direct measurements of ozone were made. In another study, commissioned by the American Society of Heating, Refrigeration, and Air Conditioning Engineers (ASHRAE), cabin crew were more likely to report the presence of each symptom than were passengers, although the survey response rates were poor in both groups $(26 \%$ for cabin crew and $43 \%$ for passengers), and only eight flights were studied. ${ }^{18}$ In a survey of 185 cabin crew members working on Asian routes, over $50 \%$ of the respondents reported moderate to severe eye, nose, or throat irritation after completion of a given flight segment. ${ }^{19}$ Symptoms were not linked to measures of cabin environmental quality. Smoking was permitted on these flights but was not taken into account in this analysis.

The indoor environment of schools has also been of increasing interest in the USA. ${ }^{4}$ High energy costs have encouraged the development of tight buildings and a reduction in the amount of outdoor air brought into schools for ventilation. Sources of indoor contaminants include synthetic materials, cleaning agents, pesticides, printing and copying devices, combustion and humidification appliances, and tobacco products. ${ }^{20}$ Results from our study and others suggest that teachers and other staff may be experiencing work related symptoms and illnesses. A study conducted among 400 employees in 12 Denver schools with no previous indoor air quality complaints reported that $27 \%$ of employees had eye symptoms, $35 \%$ had nasal symptoms, and $17 \%$ had throat symptoms during the previous work week. ${ }^{2}$ Our study did not find a high prevalence of physician diagnosed asthma among teachers, although a Canadian study found an increased rate of physician diagnosed asthma for teaching and related occupations when compared to other employed persons in Manitoba, Canada. ${ }^{21}$ Other data from the NIOSH Sentinel Event Notification Systems for
Occupational Risks (SENSOR) programme show that education services accounted for $8.7 \%$ of all work related asthma cases between 1993 and 1995. ${ }^{22}$

It is likely that the majority of referent workers had jobs in indoor environments ( $71 \%$ of women in NHIS were employed in white collar occupations). Another possible group with which to compare our data is office workers, who also experience an enclosed work environment. In the US Environmental Protection Agency's Building Assessment Survey and Evaluation (BASE) study, work related symptoms were defined as occurring at least 1-3 days per week during the previous month and improving when the respondent was away from work. ${ }^{23}$ The prevalence of dry, itching, or irritated eyes was higher $(19.9 \%)$ than in our study $(7.4-12.4 \%)$. The prevalence of stuffy/runny nose and sore/dry throat was comparable to our data. The published figures are for both sexes combined; the data for women are similar (Apte, personal communication). Thus, for eye, nose, and throat irritation, although flight attendants and teachers report more symptoms than other working women in general, their experience appears somewhat comparable to women working in indoor office environments. The difference in prevalence estimates from the NHIS and BASE studies may, in part, result from the different context and intent of these surveys. The NHIS was conducted in the respondent's home as part of a general health survey, while the BASE was conducted in the respondent's work environment as part of a study of building related symptoms. This may have resulted in artificially low estimates in NHIS and artificially high estimates from the BASE study.

This study has several limitations. The symptoms measured were self reported, and thus represent subjective evidence of health problems that might be over- or under-reported. Since the environmental quality of aircraft cabins and schools has been the subject of much recent discussion, both flight attendants and teachers might have had concerns about their work environment that led them to report more symptoms. We cannot be certain about the extent of over-reporting in our study since we have no objective measures of respiratory health with which to compare the self-reported data. The fact that the study was described to potential participants as a study of reproductive health, not a study of indoor air quality, is a benefit in this regard since awareness of study objectives would not have influenced the findings.

Some of the comparison data that we used for reference were collected as long ago as the mid to late 1980s, while the study data were collected in 1999-2001. If the prevalence of respiratory symptoms has increased over time, then the actual differences may not be as large as we observed. There is little evidence that the specific symptoms we studied have, 
in fact, increased over time, although there are reports of a general trend of increasing atopy and asthma in adults in the past 20 years. ${ }^{24}$ Our study did not collect individual information about atopy. However, we have no reason to suspect that the prevalence of atopy would be different in the working populations studied. It could also be argued that atopy (like asthma) may be less prevalent among flight attendants if atopic individuals are self selected out of the occupation, which would result in an underestimate of the true prevalence.

Another limitation is the lack of any direct environmental measures with which to link the reported symptoms. Because the primary purpose of the study was to investigate reproductive health issues, air quality measurements were not part of the original study design. As a follow up to the current study, however, detailed flight histories will be obtained for the participating flight attendants and will be examined with respect to symptom prevalence. Certain aspects of the individual's flight history, such as flight hours worked and aircraft type may be important predictors of symptoms.

Sociodemographic differences between the study and the referent populations may have led to inaccurate conclusions. For example, the reference estimates for chest illness were derived from a population of female blue collar workers, who would have differed substantially from our occupational groups in a number of demographic characteristics, such as educational level. Educational level, if associated at all, shows an inverse relation with symptom reporting in studies of office workers, ${ }^{25}$ so the differences would presumably have been even larger if educational level had been equal in the three groups.

Overall, results from this study suggest that both flight attendants and teachers experience higher rates of work related upper respiratory symptoms, wheezing, chest illness, and cold or flu compared to other working women, although the prevalence of upper respiratory symptoms appears somewhat comparable to that found in indoor office environments. The findings should be confirmed and potential causes of the apparently high prevalence of symptoms in these occupational groups should be the subject of further study.

\section{APPENDIX: RESPIRATORY SYMPTOM QUESTIONS USED IN ANALYSIS}

(1) During the past two weeks, have you had any episodes of itchy, irritated, or watery eyes?

(a) How many days during the past two weeks did you have itchy, irritated, or watery eyes?

(b) Were these symptoms due to a cold or flu, allergies including hay fever, pink eye or conjunctivitis, eye strain, cosmetics, or something else?

(c) Did you have these symptoms while you were at work?

(d) While you were away from work, did these symptoms increase, decrease, or stay the same?

(2) During the past two weeks, have you had any episodes of stuffed, blocked, itchy, or runny nose?

(a) How many days during the past two weeks did you have a stuffed, blocked, itchy, or runny nose?

(b) Were these symptoms due to a cold or flu, allergies including hay fever, sinuses, adenoids or deviated septum, or something else?

(c) Did you have these symptoms while you were at work? (d) While you were away from work, did these symptoms increase, decrease, or stay the same?

(3) During the past two weeks, have you had any episodes of sore or dry throat?

(a) How many days during the past two weeks did you have a sore or dry throat?

(b) Were these symptoms due to a cold or flu, allergies including hay fever, side effect of medication, excessive use of your voice, or something else?

(c) Did you have these symptoms while you were at work?

(d) While you were away from work, did these symptoms increase, decrease, or stay the same?

(4) Have you had a wheezing or whistling in your chest at any time in the past 12 months?

(5) In the past 12 months, how many episodes of cold or flu have you had?

(6) Have you ever had asthma?

(a) Was it confirmed by a doctor?

(b) Do you still have asthma?

(7) During the past three years, have you had any chest illness which has kept you from your usual activities for at least a week?

\section{ACKNOWLEDGEMENTS}

This study was supported, in part, by interagency agreements with the Federal Aviation Administration and the Department of Defense Women's Health Research Program.

We wish to thank the women who participated in this study. We appreciate the assistance of the study airlines and the school districts; the Air Transport Association; Dr James Whinnery and the late Dr Jerry Hordinsky of the Federal Aviation Administration; the Association of Flight Attendants and its Seattle Local 19; the Association of Professional Flight Attendants and its Miami representatives; the International Brotherhood of Teamsters, Airline Division, and its Detroit representatives; the National Education Association and its Seattle, Grand Rapids, and Pinellas County representatives.

\section{Authors' affiliations}

E A Whelan, C C Lawson, B Grajewski, M R Petersen, L E Pinkerton, E M Ward, T M Schnorr, National Institute for Occupational Safety and Health, Division of Surveillance, Hazard Evaluations and Field Studies, Cincinnati, Ohio, USA

\section{REFERENCES}

1 National Research Council. The airliner cabin environment and the health of passengers and crew. Washington, DC: National Academy Press, 2001

2 Kinshella MR, Van Dyke MV, Douglas KE, et al. Perceptions of indoor air quality associated with ventilation system types in elementary schools. Appl Occup Environ Hyg 2001; 16:952-60.

3 Hocking MB. Indoor air quality. Recommendations relevant to aircraft passenger cabins. AlHA J 1998:59:446-54.

4 Alexander DL. School employees: the forgotten municipal workers. Occup Med 2001; 16:65-78

5 Whelan EA, Grajewski B, Wood E, et al. Feasibility issues in reproductive biomonitoring of female flight attendants and teachers. J Occup Environ Med 2002:44:947-55.

6 Massey JT, Moore TF, Parsons VL, et al. Design and estimation for the National Health Interview Survey, 1985-1994, National Center for Health Statistics Series 2, No. 110. DHHS Publication No. (PHS) 89-1384. Washington, DC: DHHS.

7 US Department of Health and Human Services, National Center for Health Statistics. Third National Health and Nutrition Examination Survey, 1988-94, Reference manuals and reports (CD-ROM). Hyattsville, MD: Centers for Disease Control and Prevention, 1996.

8 Medical Research Council. Committee on the etiology of chronic bronchitis: standardized questionnaire on respiratory symptoms. BMJ 1960;2:1665.

9 Petersen M, Castellan RM. Prevalence of chest symptoms in nonexposed bluecollar workers. J Occup Med 1984;26:367-74. 
10 CDC. Self-reported asthma prevalence among adults-United States, 2000 MMWR 2001;50:682-6.

11 Shah BV, Barnwell BG, Bieler GS. SUDAAN user's manual, release 7.5. Research Triangle Park, NC: Research Triangle Institute, 1997

12 SAS Institute Inc. SAS language reference: dictionary, version 8. Cary, NC: SAS Institute Inc., 1999.

13 Seppänen OA, Fisk WJ, Mendell MJ. Association of ventilation rates and $\mathrm{CO}_{2}$ concentrations with health and other responses in commercial and institutional buildings. Indoor Air 1999:9:226-52.

14 Hocking MB. Trends in cabin air quality of commercial aircraft: industry and passenger perspectives. Rev Environ Health 2002;17:1-49.

15 van Netten C. Analysis of two jet engine lubricating oils and a hydraulic fluid: their pyrolytic breakdown products and their implication on aircraft air quality. In: Nagda NL, ed. Air quality and comfort in airliner cabins. West Conshohocken, PA: American Society for Testing and Materials, 61-75.

16 van Netten C, Leung V. Comparison of the constituents of two jet engine lubricating oils and their volatile pyrolytic degradation products. Appl Occup Environ Hyg 2000;15:277-83.

17 Tashkin DP, Coulson AH, Simmons MS, et al. Respiratory symptoms of flight attendants during high-altitude flight: possible relation to cabin ozone exposure. Int Arch Occup Environ Health 1983;52:117-37.

18 Pierce WM, Janczewski JN, Roethlisberger B, et al. Air quality on commercial aircraft. ASHRAE J 1999:26-34.
19 Lee SC, Poon CS, Li XD, et al. Questionnaire survey to evaluate the health and comfort of cabin crew. In: Nagda NL, ed. Air quality and comfort in airliner cabins, ASTM STP 1393 West Conshohocken, PA: American Society for Testing and Materials, 2000

20 United States Environmental Protection Agency. Environmental hazards in your school. A resource handbook, Publication 2DT-2001, October 1990.

21 Kraut A, Walld R, Mustard C. Prevalence of physician-diagnosed asthma by occupational groupings in Manitoba, Canada. Am J Ind Med 1997;32:275-82.

22 US Department of Health and Human Services, Centers for Disease Control and Prevention, National Institute for Occupational Safety and Health, Division of Respiratory Disease Studies. Work-related lung disease surveillance report. 1999.

23 Apte MG, Fisk WJ, Daisey JM. Associations between indoor $\mathrm{CO}_{2}$ concentrations and sick building syndrome symptoms in U.S. office buildings: an analysis of the 1994-1996 BASE study data. Indoor Air 2000;10:246-57.

24 Upton MN, McConnachie A, McSharry C, et al. Intergenerational 20 year trends in the prevalence of asthma and hay fever in adults: the Midspan family study surveys of parents and offspring. BMJ 2000;321:88-92.

25 Nelson N, Kaufman JD, Burt J, et al. Health symptoms and the work environment in four non-problem United States office buildings. Scand J Work Environ Health 1995;21:51-9.

\section{WORLD AT WORK}

\section{A new series}

n this issue of Occupational and Environmental Medicine we are beginning a new series of occasional articles called World at Work. These short articles are intended to give readers some of the same sort of understanding of jobs, workplaces, and their hazards that they would get from a workplace visit with a knowledgeable person. A good workplace visit is a fascinating and informative experience and we hope articles in the World at Work series will be the next best thing for our readers. An important feature of the articles in the series will be the illustrations of the workplace tasks and hazards. As well as still photographs we will increasingly be including short video clips. We can even include sound if it makes a point!

In the series we intend to feature important and common workplaces, as well as interesting and unfamiliar work settings, from all over the world. Articles will not necessarily appear every month, but we hope to keep up a regular flow. At the beginning most of the articles have been commissioned, but we welcome suggestions for articles in the series from anyone interested to contribute one. Please contact us to let us know which workplace you would like to cover, so that we can avoid duplication, and we will send instructions for how the article should be prepared. This is a good opportunity to share your expert knowledge about a particular workplace with colleagues around the world.

I hope you will enjoy this new series. Please send us your feedback about it. The first article, "Hazards and controls in aluminium potrooms" appears on page 989 of this issue.

Anne Cockcroft Editor, OEM 